\title{
Screening of Rice (Oryza sativa L.) for Salinity Tolerance at Vegetative Stage under Hydroponic Condition
}

\author{
Chhavi*, D. K. Dwivedi, Gaurav Kumar, Akanksha Singh and Avinash K. Singh \\ Department of Plant Molecular Biology \& Genetic Engineering, N.D. University of \\ Agriculture \& Technology, Kumarganj, Faizabad-224229, India \\ *Corresponding author
}

\section{A B S T R A C T}

\section{Keywords \\ QTL: qualitative trait loci, Allele: contrasting pair of gene, EC: electrical conductivity, Hydroponic condition: soil-less culture \\ Article Info \\ Accepted: \\ 17 May 2018 \\ Available Online: \\ 10 June 2018}

Rice is one of the most suitable crop for saline soils although it is usually considered moderately sensitive to salinity. In this study, the phenotypic response of ten rice genotypes with salt stress at $\mathrm{EC}=12 \mathrm{dsm}^{-1}$ was assessed under hydroponic condition at seedling stage. The rice genotypes CSR-13 and CSR-30 showed highly tolerance to salinity; genotypes NDRK-5088, NUD-2, NUD-3, FL478 and CSR-90IR-2 were recorded moderately salinity tolerance and varieties NDR-359, IR-29 and IR-28 showed susceptibility to salinity. Tolerant varieties are suggested to use as donor parents for salinity tolerance in back cross breeding and for allele mining for salinity tolerance gene/QTLs

\section{Introduction}

The plant response to salinity consists of various processes that must function in coordination to enhance both cellular hyperosmolarity and ion disequilibrium. Salt stress adversely affects agricultural yield throughout the world affecting production.

Many species of higher plants, including most crops, are subjected to growth inhibition under high- $\mathrm{NaCl}$ condition. Rice is one of the most suitable crop moderately sensitive to salinity (Akbar et al., 1972). It is relatively tolerant to salinity at the germination stage but its panicle initiation and pollination stage are two most salinity-sensitive growth stages which is directly related to crop yield (Heenah et al., 1988, Khatun and Flower, 1995, Zeng et al., 2001).

Screening of rice genotypes at seedling stage is comparatively easier than reproductive stage and also rapid. It is very difficult at the reproductive stage (Gregario et al., 1997).

The typical mechanism of salinity tolerance in rice is the exclusion or reduction of $\mathrm{Na}$ uptake and increased absorption of $\mathrm{K}$ to maintain a $\operatorname{good} \mathrm{Na}^{+}-\mathrm{K}^{+}$balance in the shoot. The visual symptoms of salt stress may still be the most appropriate for mass screening. Salt injury 
starts with reduction in effective leaf area. The oldest leaves starts to roll then die, followed by the next older, and so on. Rice is very sensitive to salinity at seedling stage. Its height, root length, emergence of new roots and dry matter decreases significantly at EC 5$6 \mathrm{dSm}^{-1}$ (Pearson et al., 1966, Akbar and Yabuno, 1974). Salinity suppresses leaf elongation and formation of new leaves.

Photosynthetic function and chlorophyll content were inversely proportional to salinity level (Ota and Yasue, 1962). The screening technique is based on the ability of seedling to flourish in salinized nutrient solution.

\section{Materials and Methods}

\section{Plant materials}

Total ten rice genotypes were used in this study, which were NUD-2, NUD-3, NDRK5088, NDR-359, CSR-13, CSR-30, CSR90IR-2, FL-478, IR-28 and IR-29.

\section{Preparation of stock solution}

Proper preparation of stock solutions is essential to avoid nutrient deficiencies and mineral toxicities not attributed to salinity stress. Therefore, the amounts prepared should depend on the number of test entries screened during a two-month period. Details for preparing $1 \mathrm{~L}$ of stock solutions are presented in Table I. For the macronutrient stock solutions, weighed the required amount of reagent (Table1) and transfer to a 1000-ml beaker and initial mixing was done with $750 \mathrm{ml}$ distilled water. Then mixture was transferred to 2-L volumetric flask, then added distilled water and make up volume $2 \mathrm{~L}$. Shake the mixture for $15 \mathrm{~min}$ using a magnetic stirrer then transferred to stock solution bottle. Preparation of micronutrient stock solution is critical because most nutrient deficiencies and other toxicities could be traced to improper preparation. Each reagent of the micronutrient solution listed in Table 1 should be dissolved separately. Mixed all solutions together in distilled water using volumetric flask. Added the ferric chloride solution to the mixture just before citric acid and stirred the mixture for 15 min using a magnetic stirrer. Finally added $100 \mathrm{ml}$ sulfuric acid to the mixture and maked up volume to $2.0 \mathrm{~L}$. Stirred for another $10 \mathrm{~min}$ and stored in a dark glass bottle. The final color of this solution was yellowish brown.

\section{Salinization of nutrient solution}

Salinized the nutrient solution by adding $\mathrm{NaCl}$ while stirring up to the desired EC. Filled up the trays with this solution high enough to touch the nylon net bottom of the thermocol.

\section{Results and Discussion}

The rice genotypes were screened in the lab condition in Yoshida (1976) solution. The rice genotype scored for salinity tolerance at seedling stage based on Standard Evaluation System (SES), 1996 at 7, 14 and 21 days after salinization. The data revealed that all the varieties showed highly salinity tolerance to tolerance with score of 1 to 3 after 7 days of salinization. Varieties NUD-3, NDRK-5088, NUD-2, CSR-30, CSR-13 and CSR-90IRexhibited high salinity tolerance with salinity score of 1 and NDR 359, IR 28 and IR 29 exhibited salinity tolerance with score 3 . After 14 days of salinization varieties CSR- 30, CSR-13, CSR 90-IR2 and FL 478 showed tolerance to salinity; varieties Narendra Usar Dhan- 2, Narendra Usar Dhan- 3 and NDRK 5088 were recorded moderately salinity tolerance with score 5 and varieties IR 28, NDR 359 and IR 29 showed susceptibility to salinity with score 7 . 
Table.1 Preparation of stock solution

\begin{tabular}{|l|l|l|}
\hline $\begin{array}{l}\text { Element } \\
\text { Micronutrient }\end{array}$ & Reagent & Preparation (g/L) \\
\hline $\mathbf{N}$ & Amonium nitrate & 91.4 \\
\hline $\mathbf{P}$ & Sodium phosphate, monobasis monohydrate & 35.6 \\
\hline K & Potassium sulphate & 71.4 \\
\hline Ca & Calcium chloride, dehydrate & 117.35 \\
\hline Mg & Magnesium sulphate, 7- hydrate & 324 \\
\hline Micronutrient & & \\
\hline Mn & Maganous chloride,4-hydrte & 1.5 \\
\hline Mo & Ammonium molybdate,4-hydrate & 0.074 \\
\hline Zn & Zinc sulphate,7-hydrate & 0.035 \\
\hline B & Boric acid & 0.934 \\
\hline Cu & Cupric sulphate,5-hydrate & 0.031 \\
\hline Fe & Ferric chloride,6-hydrate & 7.7 \\
\hline & $\quad$ Citric acid, monohydrate 11.9 & \\
\hline
\end{tabular}

Source: Yoshida et al., (1976)

Table.2 Salinity score at vegetative stage in lab condition

\begin{tabular}{|c|c|c|c|c|}
\hline \multirow[t]{2}{*}{ S. No. } & \multirow[t]{2}{*}{ Varieties } & \multicolumn{3}{|c|}{ Salinity score } \\
\hline & & 7 days & 14 days & 21 days \\
\hline 1 & NUD-3 & 1 & 5 & 5 \\
\hline 2 & NDRK-5088* & 1 & 5 & 5 \\
\hline 3 & NUD-2* & 1 & 5 & 5 \\
\hline 4 & NDR-359* & 3 & 7 & 9 \\
\hline 5 & CSR-30** & 1 & 3 & 5 \\
\hline 6 & IR-29* & 3 & 7 & 9 \\
\hline 7 & CSR-13** & 1 & 3 & 5 \\
\hline 8 & IR-28** & 3 & 7 & 9 \\
\hline 9 & CSR-90-IR-2 & 1 & 3 & 5 \\
\hline 10 & FL-478 & 3 & 3 & 5 \\
\hline
\end{tabular}

After 21 days of salinization NUD-3, NDRK5088, NUD-2, CSR-13, CSR-30, CSR-90IR-2 and FL 478 showed susceptibility response to salinity whereas, varieties NDR-359, IR-29 and IR-28 were highly susceptibe to salinity (Table 2). Gregario et al., (2002) observed wide variation in for salinity tolerance in rice accessions and also reported with FL-478 and NSIC Rc222 as tolerant variant of cross Pokalli (tolerant) and IR-29 (sensitive).

\section{References}

Akbar, M., and T. Yabuno. (1974). Breeding for saline-resistant varieties of rice. II. Comparative performance of some rice varieties to salinity during early developing stage. Jpn. J. Breed., 24(4): 176-181.

Gregario, G.B., Senadhira, D., Mendoza, R.D., Manigbas, N.L., Roxas, J.P. and 
Guerta, C.Q. (2002). Progress in breeding for salinity tolerance and associated abiotic stress in rice. Field Crop Res. 76 (2/3): 91-101.

Gregorio, G.B., Senadhira, D. and R.D. Mendoza. (1997). Screening rice for salinity tolerance. IRRI Discussion Paper Series no. 22. Manila (Philippines): International Rice Research Institute. pp. 1-30.

Heenan, D. P., Lewin, L. G. and D.W. McCaffery. (1988). Salinity tolerance in rice varieties at different growth stages. Aust. J. Exp. Agric., 28: 343-349.
Powar, S.L. and V.B. Mehta. (1997). Integrated nutrient Management for rice in coastal saline soil of high rainfall area. Ann. Agril. Res., 18(4): 538-540.

Yoshida. S., D.A. Forno, J.H. Cook and K.A. Gomez. (1976). Laboratory manual for physiological studies of rice. International Rice Research Institute (IRRI), Los Baños, Laguna, Philippines. p. 61-66.

Zeng, L., M.C. Shannon and S.M. Lesch. (2001). Timing of salinity stress affects rice growth and yield components. Agric. Water Manage. 48: 191-206.

\section{How to cite this article:}

Chhavi, D. K. Dwivedi, Gaurav Kumar, Akanksha Singh and Avinash K. Singh. 2018. Screening of Rice (Oryza sativa L.) for Salinity Tolerance at Vegetative Stage under Hydroponic Condition. Int.J.Curr.Microbiol.App.Sci. 7(06): 1539-1542.

doi: https://doi.org/10.20546/ijcmas.2018.706.183 